\title{
Necesidad de una política nacional para el control de las enfermedades crónicas no transmisibles
}

\section{Need for a national policy trying to control chronic non- communicable diseases}

Correspondencia

RayTicse Aguirre

ray.ticse@upch.pe

\author{
Ray Ticse ${ }^{1,2}$, Camila Gonzalez-Olaechea ${ }^{1}$ \\ 1 Subcomité de Enfermedades Crónicas, Colegio Médico del Perú. Lima, Perú. \\ 2 Servicio de Endocrinología, Hospital Cayetano Heredia. Lima, Perú.
}

\section{Sr. Editor:}

Las enfermedades crónicas no transmisibles (ECNT), fundamentalmente las cardiovasculares, la obesidad, el cáncer, la diabetes y las enfermedades respiratorias crónicas, constituyen la principal causa de muerte en la Región. En el 2007 se registraron unos 4,45 millones de defunciones por estas enfermedades, de las cuales un $37 \%$ se produjeron en menores de 70 años [1].

La disminución de la mortalidad no sólo depende de mejorar el acceso a los servicios de salud o brindar tratamiento o fármacos específicos, sino también de la aplicación de políticas de estado en salud pública y programas de control, especialmente aquellos que se centran en factores de riesgos considerados comunes y críticos, como son la nutrición, actividad física, el consumo de tabaco y educación [2,3].

En el Perú se observa el incremento de la prevalencia de estas enfermedades [4] y existen factores que son influyen en el incremento de su prevalencia, son considerados transversales a otros problemas de afecta a la sociedad:

(a) Urbanización no planificada: El crecimiento de las zonas urbanas, de manera no planificada, traen consigo los retos de la urbanización, sobre todo para los urbanos pobres. Ausencia de parques, áreas protegidas en donde se pueda practicar deporte.

(b) Seguridad ciudadana: en ambiente de inseguridad hace que muchos padres prefieran que sus hijos permanezcan en sus hogares entretenidos en juegos electrónicos en desmedro de practicar deportes o juegos que impliquen actividad física.

(c) Alimentos procesados: es importante que se aplican formas sencillas de presentar esta información, tal como se está haciendo en otros países como Ecuadory Chile con los "semáforos" nutricionales.

(d) Primer nivel de atención sin capacidad de resolución: Es necesario que el primer nivel de atención tenga personal capacitado para realizar gestión, los médicos generales o serumistas no tienen las competencias suficientes para desarrollar estas funciones.

(e) Educación: Los colegios han reemplazado progresivamente las horas de educación física por actividades netamente académicas, siendo su oferta esencialmente el ingreso a la universidad que la formación integral.

Respecto a este último ámbito, el Ministerio de Educación del Perú (MINEDU) en respuesta a las sugerencias realizadas por el Ministerio de Salud y las recomendaciones de actividad física en la niñez 
y adolescencia de la OMS, ha emitido una resolución ministerial para poder contra restar la inactividad física escolary así mejorar el perfil metabólico [5]. Dentro de las acciones implementadas en el documento se ve el incrementar las horas de educación física escolar, fortalecer las capacidades de los profesores para garantizar el logro de los aprendizajes en los estudiantes identificando el talento deportivo, contratar mayor número de profesores de educación física y optimizar la infraestructura. Sin embargo los esfuerzos aislados de sólo los sectores educación y salud no garantizan el éxito de la prevención y disminución de la mortalidad de las ECNT.

Como conclusión, recomendamos que para el controlar el incremento de la prevalencia de la ECNT en el Perú se implemente una política nacional que incluya programas transversales a diversas áreas de la sociedad, con la participación de todos los ministerios e instituciones involucradas de manera directa o indirecta.

\section{Fuente de financiamiento:}

Los autores declaran no haber recibido ninguna financiación para la realización de este trabajo.

\section{Declaración de conflicto de intereses:}

Los autores declaran no tener conflicto de intereses con la publicación de este artículo.

\section{REFERENCIAS BIBLIOGRÁFICAS}

1. Organización Panamericana de la Salud; Organización Mundial de la Salud. 28.a Conferencia Sanitaria Panamericana. 64.A Sesión del Comité Regional [Internet]. Washington, D.C.: OPS/ OMS; 2012 [citado el 14 de marzo de 2016]. Disponible en: http:// www.paho.org/hq/index.php?option=com_docman\&task=doc_ view\&gid $=19267 \&$ Itemid

2. Recommended citation: Halpin HA, Morales-Suárez-Varela MM, Martin-Moreno JM. Chronic disease prevention and the new public health. Public Health Reviews 2010;32(1):120-54.

3. Gaede $P$, Vedel P, Larsen N, Jensen GV, Parving HH, Pedersen $O$. Multifactorial intervention and cardiovascular disease in patients with type 2 diabetes. N Engl J Med. 2003;348(5):383-93.

4. Instituto Nacional de Estadística e Informática (INEI). Encuesta Demográfica y de Salud Familiar-ENDES. Lima; INEI; 2014.

5. Perú, Ministerio de Educación. Resolución Ministerial del MINEDU 034-2015: Plan Nacional de fortalecimiento de la Educación Física y el deporte escolar. Lima: MINEDU; 2015. 